\title{
O INTERACIONISMO EM AQUISIÇÃO DE LINGUAGEM COMO UM LUGAR DE INVESTIGAÇÃO PARA A ESCRITA INFANTIL
}

\section{INTERACTIONISM IN LANGUAGE ACQUISITION AS A NEW THEORETICAL PLACE FOR CHILDREN'S WRITING}

\author{
Magda Wacemberg Pereira Lima Carvalho ${ }^{1}$
}

\begin{abstract}
RESUMO
Este trabalho consiste em apresentar o interacionismo em aquisição de linguagem como alternativa à investigação da aquisição da linguagem escrita, uma vez que essa proposição articula um referencial teórico que possibilita a abertura de uma nova perspectiva de análise fundamentada na relação sujeito/língua. Partimos, então, do movimento feito pela pesquisadora brasileira Cláudia de Lemos, em busca de uma teoria de linguagem que analisasse o percurso linguístico da criança e, também, de sua articulação entre a linguística estruturalista de base europeia e a psicanálise lacaniana, proposta que influenciou os trabalhos de Sônia Borges e Zelma Bosco. Nessa perspectiva, na tentativa de exemplificar a aquisição da escrita com base no interacionismo em aquisição de linguagem, recorremos a textos já analisados e discutidos por essas duas últimas autoras. Observamos que, na travessia da criança pela aquisição da escrita, os escritos do outro funcionam como um espelho para a criança no início do percurso de aquisição da linguagem escrita, em razão de a materialidade dos diversos textos e a interação da criança com essa materialidade facilitarem o aparecimento de aspectos gráficos e textuais na escrita inicial da criança.
\end{abstract}

PALAVRAS-CHAVE: Aquisição da Linguagem; Aquisição da Escrita; Interacionismo.

\begin{abstract}
This work consists of presenting interactionism in language acquisition as an alternative to the investigation of written language acquisition, since this proposition articulates a theoretical framework that allows the opening of a new perspective of analysis based on the subject/language relationship. We've started, then, from the movement made by the Brazilian researcher Cláudia de Lemos, in search of a theory that analyzed the child's linguistic path and, also, of its articulation between European-based structuralist linguistics and Lacanian psychoanalysis, a proposal that influenced the works of Sônia Borges and Zelma Bosco. In this perspective, in an attempt to exemplify the acquisition of writing based on interactionism in language acquisition, we've resorted to texts already analyzed and discussed by these last two authors. We observed that, in the child's journey through the acquisition of writing, the writings of others act as a mirror for the child in the beginning of the path of acquisition of written language, because the materiality of the various texts and the child's interaction with this materiality facilitate the appearance of graphic and textual aspects in the child's initial writing.
\end{abstract}

KEYWORDS: Language Acquisition; Acquisition of Writing; Interactionism.

\footnotetext{
${ }^{1}$ Doutora em Ciências da Linguagem, pela da Universidade Católica de Pernambuco (UNICAP). Professora da Rede Pública de Ensino de Pernambuco. Recife/PE. E-mail: magdapcarvalho@,hotmail.com
} 


\section{INTRODUÇÃO}

O interacionismo em aquisição de linguagem é uma proposta teórica que surgiu a partir da inquietação da pesquisadora brasileira Cláudia de Lemos em busca de uma teoria da linguagem que desse conta dos impasses acerca da investigação do percurso linguístico da criança.

O relato do esforço teórico da autora foi apresentado no texto "Das vicissitudes da fala da criança e de sua investigação" (2002), em que trata de sua relação com a fala inicial infantil, ou melhor, refere-se tanto "às mudanças que a fala da criança pode mostrar quanto às mudanças de posição do investigador ao discerni-las" (LEMOS, 2002, p. 41).

Nesse texto, a autora diz que o primeiro passo na tentativa de analisar a fala de crianças que a levou ao impasse foi quando, ao investigar aspectos da predicação do Português, observou que as ocorrências dos verbos "ser" e "estar" eram limitadas na fala infantil e, além disso, havia nessa fala "fragmentos do enunciado precedentes do adulto" (LEMOS, 2002, p. 44), o que lhe pareceu como algo que resistia à sistematização e que aparentava ganhar certa eficiência através da interpretação do adulto.

Diante disso, atribuindo o estatuto de enigma à fala da criança e com o objetivo de dar status menos descritivo à investigação sobre essa fala, a autora propôs a noção de processos dialógicos. Nesse momento de teorização, diante do que observou nos episódios de fala entre a criança e o adulto, Lemos nomeou os processos dialógicos como processo de especularidade, reciprocidade e complementaridade. No entanto, os dois últimos processos foram deixados de lado pela autora, pois tanto a reciprocidade quanto a complementaridade se davam através da especularidade por meio do retorno da fala do adulto na fala da criança.

Mais tarde, em "Los procesos metafóricos y metonímicos como mecanismos de cambio" (1992), Lemos muda o rumo de sua proposta e, a partir da releitura de Saussure, passa a considerar que há algo sobre o funcionamento da língua na fala inicial, isto é, algo sobre a ordem própria da língua é "revelado pelos 'erros' enquanto produtos de relações entre cadeias que se cruzam produzindo substituições" (LEMOS, 2002, p. 51). Convém acrescentar que o texto de Roman Jakobson, "Dois aspectos da linguagem e dois tipos de afasia" (2008 [1954]), sobre os processos metafóricos e metonímicos foi determinante para que a autora apreendesse "a linguagem em seu estado nascente na fala da criança, assim como o movimento que produziria a mudança" (LEMOS, 2002, p. 52). Com isso, Lemos propõe que as mudanças ocorridas na fala inicial da criança são mudanças de posição em relação à fala do outro (adulto), à língua e à sua própria fala, definida por ela como

mudança de posição em uma estrutura, no sentido em que não há superação de nenhuma das três posições, mas uma relação que se manifesta, na primeira posição, pela dominância da fala do outro, na segunda posição, pela dominância do funcionamento da língua e, na terceira posição, pela dominância da relação do sujeito com sua própria fala (LEMOS, 2002, p. 56, grifos da autora).

Nesse sentido, na posição em que o polo dominante é o outro, a autora observa o retorno na fala da criança de parte dos enunciados do outro (adulto). Na segunda posição, em que o polo dominante é a língua, a autora diz que os enunciados da criança "são cadeias permeáveis a outras cadeias e, portanto, passíveis de deslocamento, de ressignificação" (LEMOS, 2002, p. 61), já quando comparecem pausas, reformulações e correções na fala da criança Lemos assinala como sendo o polo que caracteriza a relação do sujeito com sua própria fala, isso porque a reorganização do enunciado dito pela criança indica a mudança de posição entre a instância que fala e a que escuta.

Assim, a visão estrutural da mudança foi a proposição que melhor respondeu às questões que inquietavam a autora quanto ao percurso linguístico da criança, uma vez que essa proposta permite ao investigador reconhecer o imprevisível que irrompe na fala inicial como resultado da 
mudança de posição da criança de infans a sujeito falante, mudança essa que é singular a cada criança.

Cabe ressaltar que apesar de o trajeto de Cláudia de Lemos ter sido motivado por suas questões em relação à fala da criança, a concepção de uma visão estrutural de mudança fundamentada na articulação entre a linguística estruturalista de base europeia e a psicanálise lacaniana, também, oferece suporte para a investigação da aquisição da linguagem escrita, visto que permite investigar o movimento de travessia da criança, quer dizer, possibilita observar o movimento para frente e para trás feito pela criança na escrita, quando ela vai do registro de rabiscos e desenhos para o registro com letras e desse para o desenho. Nessa perspectiva, o conceito de mudança de posição não qualifica apenas "a trajetória da criança de infans a sujeitofalante" (LEMOS, 2002, p. 56), mas também da mudança de estatuto da criança de nãoescrevente para escrevente.

Nesse sentido, julgamos importante a apresentação algumas considerações acerca da escrita infantil para o interacionismo em aquisição de linguagem.

\section{Sobre a perspectiva interacionista}

Para Cláudia de Lemos, a linguística não deve ser vista sob a forma de certezas e respostas às questões colocadas pelo processo de alfabetização, mas "como lugar onde o que não se sabe sobre a linguagem é reconhecido e produz questões" (LEMOS, 1998, p. 8, grifos da autora).

Desse modo, é a partir das questões que se colocam para quem elege as produções infantis como unidade de análise, no dizer de Lemos, enigmas que interrogam o investigador, que o interacionismo, como postulado por essa autora no campo da aquisição de linguagem, apresenta-se como um lugar teórico para a observação da escrita infantil.

No entanto, cumpre dizer que os desdobramentos dessa teoria, na investigação da escrita inicial, devem-se em especial aos trabalhos de Sônia Borges $(1995 / 2005,2010)$ e Zelma Bosco (2002, 2005, 2009), que, assumindo o compromisso de investigar o percurso da criança na escrita, compreendem o contato com textos escritos de natureza diversa, fornecidos pelo outro, como sendo de fundamental importância para a aquisição da escrita, em razão de que a interação com textos ser o que vai permitir "a emergência dos aspectos gráfico-textuais nas produções iniciais da criança”" (BOSCO, 2005, p. 46).

Diante dessa compreensão, as autoras reconhecem as primeiras manifestações da escrita da criança como sendo de ordem linguística, o que as distancia da abordagem do processo de aquisição da escrita orientado pela noção de desenvolvimento e também da noção de escrita como representação da linguagem oral.

Em vista disso, convém realçar que antes dessas autoras tratarem sobre o tema, Cláudia de Lemos já havia abordado a questão da escrita em um seminário sobre Alfabetização (1984), em que disse pensar a escrita a partir dos "processos pelos quais a linguagem oral é adquirida" (LEMOS, 1984, p. 2), vez que esses processos poderiam iluminar a reflexão ou o debate sobre como a linguagem escrita era adquirida ou aprendida.

Importa lembrar que, nessa época, a autora já compreendia a aquisição da fala como resultado da interação da criança com o outro (adulto), "através de processos dialógicos específicos e explicativos da construção conjunta pelo adulto e pela criança de objetos comunicativos ou partilhados" (LEMOS, 1984, p. 2), entendimento que a levou a dizer, no prefácio do livro "A concepção da escrita pela criança” (1988) - organizado por Mary Kato, que é preciso considerar a escrita enquanto prática discursiva e enquanto objeto.

Para Lemos (1988), é necessário que a escola entenda a aquisição da escrita como uma ação pedagógica processual, em que a criança deve atuar como parte integrante dessa ação, devendo-se considerar a concepção de escrita que ela construiu antes de entrar na escola. Isso porque antes de ingressar no espaço escolar e quando no início do processo pedagógico, já na 
escola, os modos de participação da criança em atos de escrever se distribuem e se diversificam, conforme a autora (1988), em atos de desenhar, que se transformam em atos de escrever ou de desenhar como quem escreve ou, então, em atos de falar que se transformam em atos de ditar ou falar como quem dita para o outro escrever. Ações que resultam das atividades realizadas entre a criança e a mãe (ou quem desempenha essa função), dado que essa última, "como adulto já significado no funcionamento da linguagem escrita, vai inserir a criança em situações de ler/mostrar livros, nas quais as primeiras histórias serão contadas para a criança" (BOSCO, 2005, p. 33).

Nesse sentido, o processo inicial de aquisição da escrita, no entender de Lemos (1988), assemelha-se ao da fala, em virtude de estar assentado na interação, ou melhor, nos processos dialógicos entre a criança e o adulto. Nessa perspectiva, o papel que a criança assume na aquisição da escrita não é o de espectador, mas o de protagonista no processo de travessia pela linguagem escrita.

No prefácio do livro "Alfabetização e Letramento: perspectivas linguísticas" - organizado por Roxane Rojo (1998), Lemos apresenta algumas questões sobre a aquisição da escrita. Nesse texto, a autora reconhece a dificuldade da escola em cumprir a tarefa de alfabetizar e de introduzir nas práticas de leitura e escrita àqueles que estão excluídos, principalmente quando o alfabetizado, ao projetar sobre o alfabetizando sua própria relação com a escrita, fica impedido, conforme a autora (1998), de 'ler' os sinais - orais e gráficos apresentados pela criança. Situação que leva essa autora a refletir sobre o modo em que se opera a transformação de/em alguém que passa a ver o que não via e é capturado pela escrita.

A partir dessa análise, Lemos diz que ao tratar a aquisição da escrita como transformação ou mudança, o que tem em mente não é um sujeito que se desenvolve a partir da construção do objeto enquanto objeto de conhecimento, mas sujeito e objeto como efeitos do funcionamento simbólico ${ }^{2}$, numa indicação de "que não se parte da interação sujeito-e-objeto, mas da linguagem" (LEMOS, 1998, p. 12). Por isso a necessidade de uma proposta que assumisse o compromisso de explicar o papel do outro, da criança e das práticas discursivas na escrita.

Dessa maneira, ao observar, nos estudos de aquisição da linguagem oral, que na fala inicial fragmentos da fala do adulto retornam na da criança e se cruzam entre si, fazendo emergir produções insólitas e imprevisíveis, Lemos vê na escrita a possibilidade de dar ao outro um lugar que não seja o de transmissor, nem o de facilitador do processo, mas o de intérprete, já que nas produções escritas iniciais algo imprevisível também comparece e demanda interpretação.

Desse modo, no percurso de aquisição da escrita, o outro é tomado como representante do funcionamento da língua constituída, cujo papel seria o de quem "se oferece ao mesmo tempo como semelhante e como diferente" (LEMOS, 1998, p. 17), em razão de que ler para a criança, interrogá-la sobre o sentido do que "escreveu" e escrever para que ela leia são situações que, segundo a autora, contribuem para a inserção da criança no movimento linguístico-discursivo da escrita.

\section{Representações simbólicas e materialidade textual na aquisição da escrita da criança: algumas reflexões}

\footnotetext{
2 O termo "simbólico" diz respeito a um dos três registros que constituem o aparelho psíquico, a saber, o Real, o Simbólico e o Imaginário (R. S. I.), em que o Imaginário "é o registro do engodo, da identificação" (CHEMAMA, 1995, p. 104), que compreende toda a abordagem freudiana acerca do narcisismo, o Simbólico corresponde a "função complexa e latente que envolve toda a atividade humana, comportando uma parte consciente e outra inconsciente, ligadas à função da linguagem e, mais especialmente, à do significante" (CHEMAMA, 1995, p. 199) e o Real ao "que não pode ser simbolizado totalmente na palavra ou na escrita" (CHEMAMA, 1995, p. 182), faltando-lhe representação psíquica.
} 
Borges, em seu trabalho de doutoramento $(1995)^{3}$, observou que as letras escritas pelas crianças de sua pesquisa apresentavam um movimento contínuo de composição e decomposição que apontavam para certa sistematicidade, embora não formassem palavras da língua escrita constituída. Diante disso, a autora (1995) questionou de onde viria essa sistematicidade e que critérios eram adotados para a escolha de letras, sinais gráficos, espaçamentos "numa escrita onde nem figuravam palavras" (BORGES, 1995, p. 1).

Para a autora, as respostas às essas questões poderiam estar nas práticas linguísticotextuais trabalhadas durante sua pesquisa em sala de aula. Assim, ao partir da suposição de que a base alfabética, colocada pela escola como objetivo primordial para a alfabetização, poderia ser construída mediante encontros "naturais" com textos, Borges (1995) promoveu a circulação, leitura e escrita de diferentes textos entre os sujeitos de sua pesquisa e obteve como resultado (nas produções de crianças que faziam apenas rabiscos ou desenhos e outras já alfabetizadas) enigmáticas combinatórias de letras com aspectos de textos.

Nesse sentido, a partir dos dados coletados, Borges tentou encontrar explicações a respeito do motivo da presença de formas gráficas tão heterogêneas e não categorizáveis na escrita de crianças. As análises desses dados levaram-na a pensar que a aquisição da escrita repete, com certa diferença, a aquisição da fala, por isso o trabalho de Lemos foi fundamental para o reconhecimento de que "subjacente à indeterminação e à fragmentação das formas presentes na escrita inicial da criança" (BORGES, 1995, p. 37) existe a presença do Outro ${ }^{4}$ (alteridade radical), com o qual a criança dialoga na escrita de seus textos, como discursos e textos, que lhe são oferecidos pelo outro (adulto).

Diante disso, a autora afirma que é preciso reconhecer o Outro na aquisição da escrita para, assim, possibilitar um novo modo de olhar para as produções da criança, bem como para o processo de alfabetização, de maneira que se compreenda que, para haver aquisição de escrita, é necessário que a criança seja colocada em situações que lhe facilitem a construção de representações sobre as formas da linguagem escrita.

No entanto, convém ressaltar que “as crianças não 'entram' na língua pelos mesmos lugares nem fazem o mesmo percurso" (BORGES, 1995, p. 52), pois cada criança é única, cada uma é singular e dispõe, conforme a autora (2006), de significantes que decorrem de sua relação com o Outro, isto é, com a linguagem. Nessa perspectiva, é preciso considerar que "antes do processo formal de alfabetização, a criança tem um saber-fazer sobre a escrita, dirigido por esquemas e estruturas que resultam e são modificados por suas ações sobre essa mesma escrita" (BORGES, 1995, p. 86). Por isso, a criança começa a escrever com letras, mesmo que não seja ainda de acordo com o previsto pela língua constituída.

Para essa autora (1995), o acesso da criança à escrita implica que se transite pelas representações sobre a língua escrita que antecedem à sua, na ordem discursiva em que a criança está inserida. Nesse entendimento, Borges parte do pressuposto de que a aquisição da escrita implica, necessariamente, representações simbólicas. Desse modo, o envolvimento em situações de leitura e escrita de textos viabiliza a emergência de representações na escrita da criança sobre o que é possível na língua constituída, logo,

é preciso que a criança represente a língua escrita ainda que pela (re) constituição de um simulacro que lhe confere estabilidade, ainda que imaginária.

\footnotetext{
${ }^{3} \mathrm{Na}$ época da escrita da Tese, a autora usava o sobrenome Mota. No entanto, optamos por referi-la como Borges devido ser esse o sobrenome pelo qual é mais conhecida no campo da Aquisição de Linguagem.

4 Esse "Outro" (grafado com "O" maiúsculo) indica uma alteridade radical e opõe-se à dimensão do outro (identificação imaginária). Segundo Chemama (1995), essa diferença de grafia tenta indicar que "o sujeito é tomado por uma ordem radicalmente anterior e exterior a ele, da qual depende, mesmo que pretenda dominá-la" (CHEMAMA, 1995, p. 156). Essa ordem não é outra se não a da linguagem, visto que é nesse campo que "o sujeito irá tentar se situar" (LACAN, 2008 [1964], p. 156).
} 
Nesse sentido, escrever para a criança é essencialmente uma atividade de imitação das representações do que é possível na escrita. Por isso, não há ruptura entre os seus atos de escrever e desenhar: os dois vêm de uma mimesis que não está fundada sobre a analogia entre substâncias, a substância do que há para ser representado e a da língua escrita (BORGES, 1995, p. 102-103).

Dessa maneira, ao tomar como referência o sentido que a psicanálise dá ao termo representação e ao considerar a compreensão saussuriana de língua como sistema, o interacionismo em aquisição de linguagem articula linguística e psicanálise e desloca a investigação sobre a escrita inicial para a linguística, permitindo, desse modo, observar a aquisição da escrita a partir da relação de constituição mútua entre linguagem oral e linguagem escrita. Com isso, a escrita é tirada da posição de materialização gráfica da fala e é colocada juntamente com a oralidade "num plano em que estariam em jogo a tríade oralidade-escrita-língua" (BORGES, 2010, p. 114). Nessa perspectiva, compreende-se que é no funcionamento da língua, ou seja, no jogo de unidades linguísticas de diversas naturezas e extensões que a escrita nascente se constituirá.

Para melhor compreensão a respeito da escrita inicial, reproduzimos a seguir alguns dos dados analisados por Borges (1995) e Bosco (2005). Vejamos:

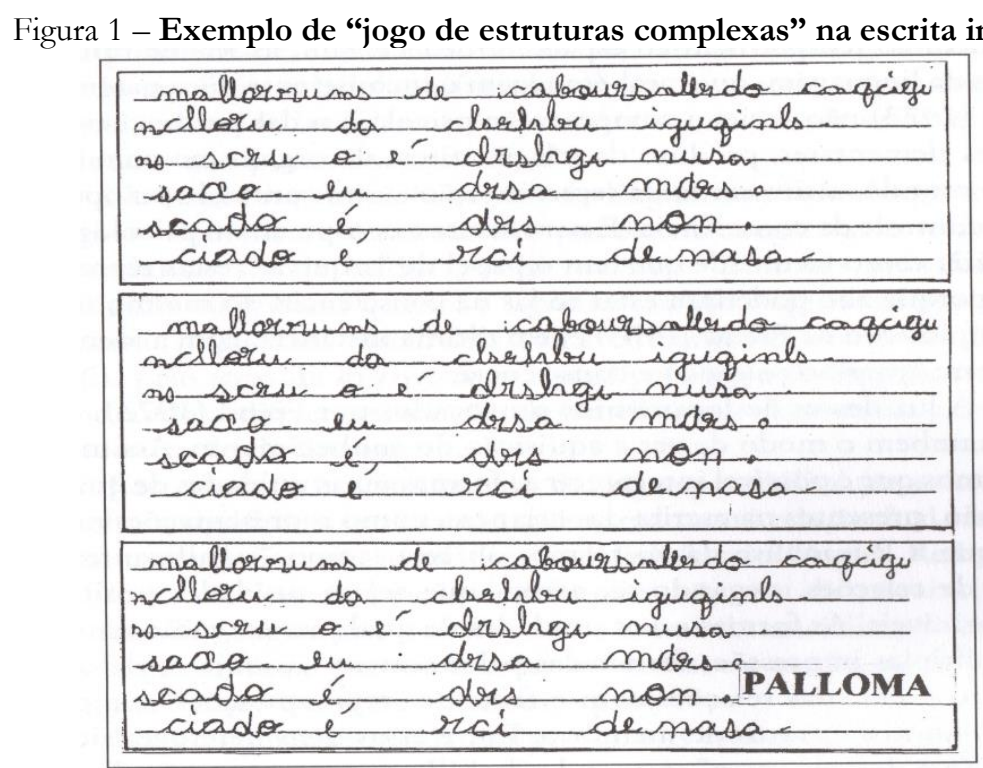

Fonte: BORGES (1995, p. 138).

Para a autora, há nesse texto um jogo de estruturas complexas em que as letras, apesar de algumas oscilações, aglutinam-se em blocos que se repetem e que aparentam estar encadeados sintagmaticamente, implicando certa ordem. Diante dessa produção, em que os trechos registrados aparecem repetidos, Borges $(1995$, p. 138) questiona se essa seria "uma consequência da intensificação das relações das crianças com textos" e reconhece a necessidade de se buscar na linguística e na psicanálise o apoio teórico para compreender se a apresentação dessa escrita é consequência ou não da relação da criança com os textos oferecidos pelo outro. Isso em razão de que as estruturas apresentadas, nessa escrita, não são simples registros que resultam de impressões sensíveis ou categorizações, mas escritos que evidenciam a relação da criança com o Outro, isto é, com os discursos orais e escritos que circulam em sala de aula e aos quais a criança teve acesso.

Dessa maneira, a autora observa que as composições presentes na produção inicial da criança não se estruturam ao acaso, "mas em um movimento que obedece aos eixos paradigmático e sintagmático" (BORGES, 1995, p. 143) da língua, o que justifica não só a 
estrutura paralelística que comparece nos textos iniciais, o ganho e a perda de letras na escrita de "palavras", mas também assinala que a escrita nascente decorre do movimento "da linguagem sobre a própria linguagem" (LEMOS, 1998, p. 167).

Nessa direção, as transformações que ocorrem na escrita inicial indicam o funcionamento da língua e, por conseguinte, a captura da criança pela materialidade do texto, isto é, pelo "trabalho da letra, enquanto alçada à condição de significante" (BORGES, 1995, p. 158, grifos da autora). Cabe dizer ainda que o interacionismo em aquisição de linguagem reconhece não só a letra propriamente dita como suporte para o significante, como também admite o desenho, em virtude de que "o próprio desenho, ele mesmo, já é efeito de linguagem; efeito de relações entre significantes" (BOSCO, 2009, p. 139).

De acordo com Bosco,

o ingresso no funcionamento da escrita passa pela tomada de um fragmento um desenho ou qualquer elemento que sirva ao escrito - ao pé da letra, sendo o seu valor representativo-figurativo apagado. Esse fragmento, esvaziado de sentido, apresenta-se como elemento de escrita por efeito do corte que a letra opera no significante (BOSCO, 2009, p. 178, grifos da autora).

Com isso, os elementos escritos - letra alfabética ou desenhos - tomados como significantes, não dispõem, segundo Bosco (2009), de um sentido já dado, mas de algo que advém como efeito de alguma coisa que surpreende, perturba e constrange o leitor.

Sobre a relação desenho-letra, Bosco (2005) diz que o traçado do desenho pode vir a entrar em relação com o da letra alfabética, permitindo lê-la como no texto reproduzido a seguir, em que a pesquisadora observa no traçado da linha que serve de base para a montanha (seta 1) a emergência da letra "B", inicial do sobrenome da criança.

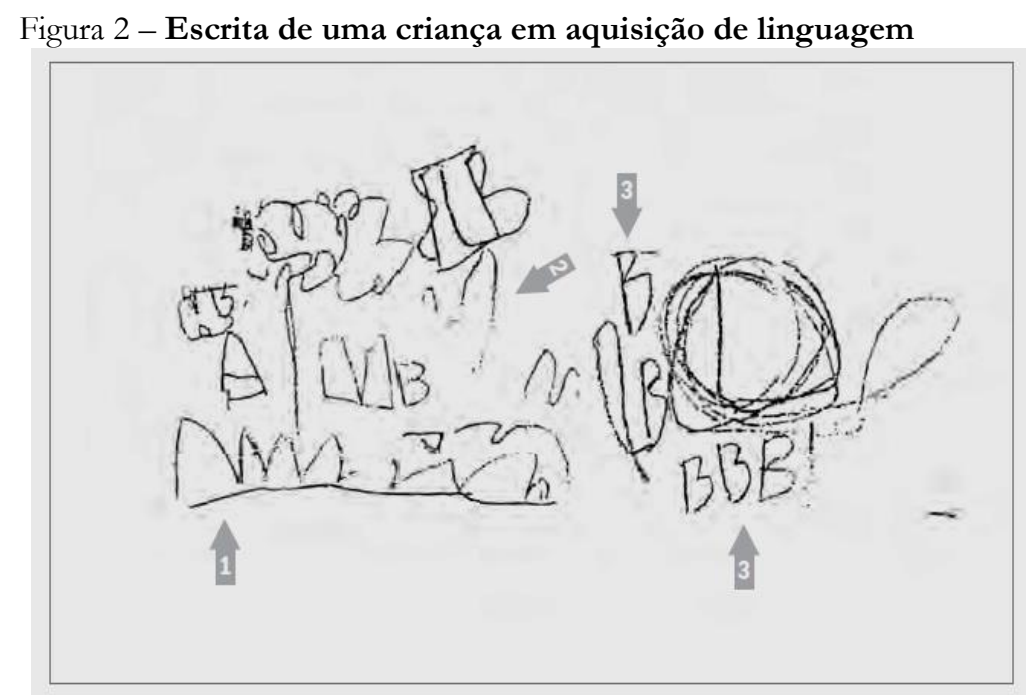

Fonte: BOSCO (2005, p. 48).

\footnotetext{
${ }^{5}$ Para o interacionismo em aquisição de linguagem, a letra alfabética pode ser compreendida como uma marca que permite o registro do significante, ou seja, permite a materialização do significante e, em consequência, abre caminho para o discurso do inconsciente, pois "é a letra que em seu caráter material imutável possibilitará tomar as formações do inconsciente como rébus" (AIRES, 2005, p. 224). O significante, por sua vez, "aponta para a diferença, abrindo novas possibilidades de significação" (AIRES, 2005, p. 224). Nesse sentido, o conceito de letra, tomado da psicanálise lacaniana, marca a repetição dos mesmos elementos, finitos, no jogo significante. Por outro lado, convém ressaltar que apesar de a letra escrita dar concretude ao significante, ela se distingue do significante, ou seja, ela não é o significante, mas o efeito dele.
} 
De acordo com Bosco (2005), a criança que produziu essa escrita identificou a letra "B" como sendo a de sua família e surpreendeu-se, ela mesma, com essa constatação. Desse modo, considerando a reação da criança ao constatar que a letra que aparece em seu desenho é a do nome de sua família, compreendemos que a criança no início do percurso de travessia pela linguagem escrita, como um sujeito que nasce marcado por um discurso que o insere na ordem humana, está suscetível ao imprevisível da língua, seja na fala ou na escrita.

Dessa maneira, o imprevisível que irrompe na fala ou na escrita inicial não é acidental, pois se trata das mudanças que qualificam "a passagem da criança de não-escrevente a escrevente" (BURGARELLI, 2003, p. 25). Com isso, é possível admitir que nas realizações linguísticas infantis "um elemento do desenho ecoa latente numa letra escrita (e vice-versa)" (BOSCO, 2009, p. 175-176), fazendo com que o nome ou letras do nome da criança irrompam na escrita.

De acordo com Bosco (2009), a emergência das letras do nome permite a ancoragem da escrita infantil em um texto e "sustenta a implicação do infans como ser singular, permitindo seu engajamento numa estrutura, pela via de um significante, a partir do qual outros efeitos estruturantes se desdobrarão" (BOSCO, 2009, p. 102).

Com isso, a escrita do nome próprio concede um lugar especial para a criança como sujeito na escrita, ou seja, o lugar daquele que escreve, visto que a realização gráfica do nome próprio é lugar de investimento do sujeito, em virtude de o nome ser o significante fundador do sujeito. Além disso, as letras do nome, segundo Bosco, possibilitam à criança o reconhecimento de outras letras como efeito de semelhança, gráfica ou sonora.

Diante desse entendimento, o trabalho de Bosco $(2002,2009)$ busca reconhecer um lugar para a escrita composta pelas letras do nome da criança. Para a autora, ao entrar em relação com significantes dos textos que circulam em sala de aula, o nome da criança, ou o que representa ser, possibilita a ressignificação do que ela escreve. Isso porque a escrita do nome começa com rabiscos, traçados indiferenciados sobre o papel até ganhar forma, linearidade e ordem. Nessa perspectiva, as letras do nome funcionam como o "significante que nomeia um sujeito em sua língua materna, e seu traçado sobre o papel resulta na realização de uma marca em que o sujeito está investido" (BOSCO, 2009, p. 20). Notemos:

Figura 3 - Escrita composta pelas letras do nome da criança

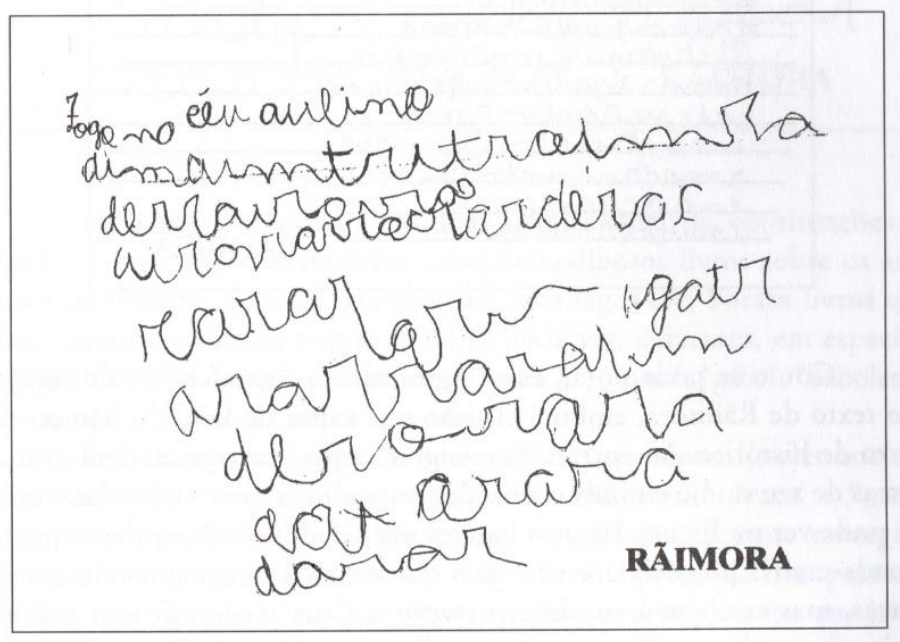

Fonte: BORGES (1995, p. 145).

Ao observarmos a organização desse texto em que as letras do nome da criança, a saber, Rãimora Rodrigues de Alcântara, aparecem encadeadas sintagmaticamente, como se formassem frases de um texto, concordamos com Bosco quando diz que "o nome escrito vai possibilitar a criação de uma materialidade significante que torna possível significar outra coisa, permitindo 
novas aquisições" (BOSCO, 2009, p. 277-278). Nesse sentido, as letras do nome fornecem à criança os elementos de uma relação inicial com a escrita, no que se refere à produção gráficotextual, que, segundo Bosco (2005), não passa, necessariamente, pela fonetização.

Ao analisar essa produção, a autora (2009) afirma que a relação da criança com textos possibilita o destaque de significantes que entram em seu texto e ressignificam sua escrita, pois ao escrever letras do nome, a criança além de se reconhecer e ser reconhecida pelo outro no que escreve, coloca as letras de seu nome em novas relações.

Com base nessa compreensão, convém realçar que as estruturas que emergem nas produções infantis, consoante Borges (1995), têm o caráter de repetição, não uma mera repetição de letras, mas uma repetição diferencial, em razão de que os significantes da criança "encontram lugar nas posições que lhe foram abertas no discurso escrito do outro" (BORGES, 1995, p. 158), indicando, dessa maneira, o acesso da criança à escrita. Contudo, é relevante acentuar que, embora seguindo o mesmo caminho, o do acesso à escrita, o registro do jogo significante é singular a cada criança.

Para Borges (1995), o que surge nessa escrita inicial formando pseudopalavras e pseudofrases resulta do efeito do discurso do Outro (alteridade radical), representado em sala de aula pelos discursos e textos que a criança tem acesso. Dessa maneira, letras e outras unidades que emergem nessa escrita assumem, conforme a autora, valores e lugares estruturais determinados pelas posições abertas no discurso do Outro.

Em vista disso, Bosco (2009) diz que há algo na escrita inicial que precisa ser "decifrado", algo que apresenta um funcionamento gráfico textual em que "as letras parecem vir à cena em sua dimensão icônica” (BORGES, 1995, p. 164). Nessas realizações linguísticas, Bosco (2009) acredita que não há um sentido já dado a ser recuperado, pois o que surge nessas realizações sucede algo que surpreende o outro. Por isso, a leitura dos escritos infantis propõe-se, segundo a autora, como deciframento e não como compreensão. Observemos:

Figura 4 - Escrita com letras e desenhos

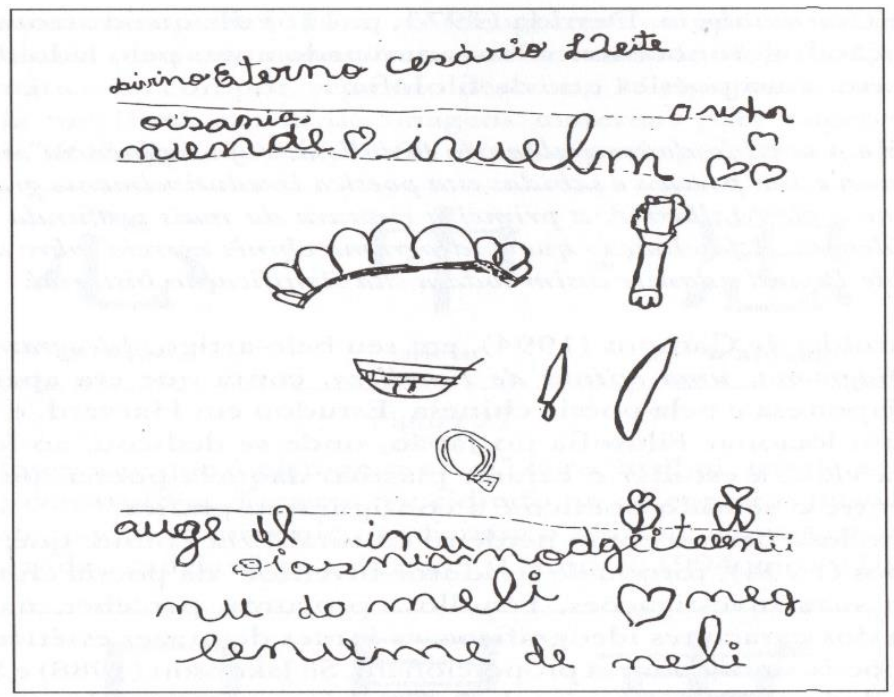

Fonte: BORGES (1995, p. 165).

Diante dessa produção, levando em conta que, conforme a autora, à criança não se impôs a regularização da escrita por significados definidos a prior ${ }^{6}$, Borges (1995) declara que a insistência da presença de letras alfabéticas na dimensão de desenho resulta do movimento de constituição do "objeto-escrita", devido a "apropriações e capturas significantes" (BORGES,

${ }^{6}$ Cabe realçar que Borges (1995) não deixa claro, em seu texto, a situação de produção deste dado, bem como não informa a idade e a escolaridade da criança. 
2010, p. 99) que a materialidade gráfica oferece para dar suporte aos discursos. Nessa perspectiva, a relação desenho-letra é compreendida como resultado do efeito da relação entre significantes, em que desenho e letra são colocados em relação de associação. Com isso, é possível reiterarmos a afirmação de que o processo de aquisição da escrita não ocorre aleatoriamente, mas como efeito do Outro, isto é, como resultado do contato da criança com a materialidade dos textos, pois são os textos apresentados pelo outro que, como espelho, orientarão a travessia da criança na passagem de não-escrevente para escrevente.

Nesse sentido, o papel do Outro na escrita nascente, conforme Borges (2010), não se limita ao de provedor de unidades, mas é também o de promoção de categorização de unidades e de constituição de estruturas, visto que as produções coletadas por essa autora, segundo ela, mostram as relações dos textos das crianças com os textos que circularam em sala de aula durante a realização de sua pesquisa.

Mas, e quando comparecem desenhos e letras amalgamados na produção infantil, seria também isso resultado do efeito do Outro nos textos da criança?

Para tratar a respeito dessa questão, podemos recorrer à noção psicanalítica de recalque ${ }^{7}$, visto que no entendimento desse campo teórico, um significante, para ser proferido, tem que recalcar outro. Mediante essa compreensão, vejamos mais um texto apresentado por Borges (1995) em que pequenos desenhos em forma de coração emergem na produção escrita:

Figura 5 - Produção escrita-desenho

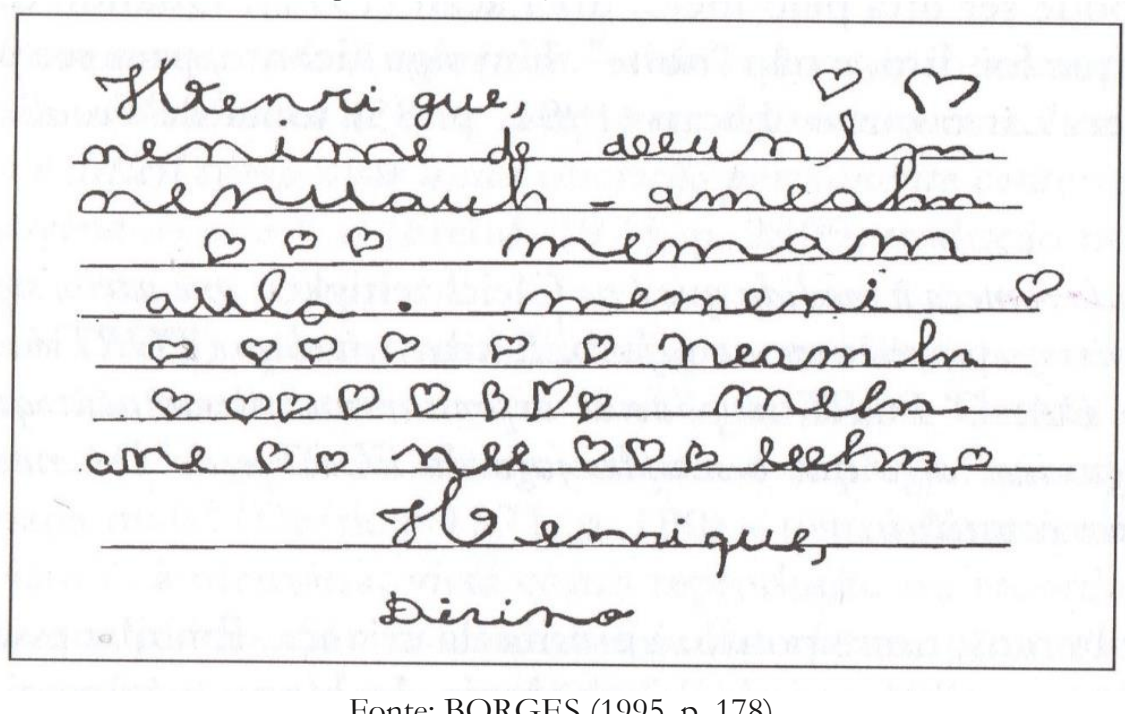

Fonte: BORGES (1995, p. 178)

Borges (1995, p. 179) diz que sob o efeito de relações imaginárias, o autor "justapõe, em seu texto, letras e corações", apresentando lugar para uma "escrita-desenho". E, embora escreva com desenhos, o que, de acordo com Bosco (2009), é efeito de linguagem, isto é, efeito de relações entre significantes, a criança atribui valor ao seu texto da mesma maneira que atribui valor aos textos que lhes são ofertados. Desse modo, a relação "entre desenho e letra é passível de ser reconhecida como efeito da combinatória de traçados" (BOSCO, 2009, p. 151), em que situações de ler e escrever, em sala de aula, fazem com que a criança recalque o desenho.

Dessa maneira, ao recalcar o desenho e escrever somente com letras, a criança "estará manifestando sua submissão ao simbólico" (BORGES, 1995, p. 181), pois, de acordo com a

\footnotetext{
7 O recalque, de acordo com Freud (1969 [1915]), é uma defesa normal, cuja essência consiste em impedir que certas representações pertencentes ao sistema inconsciente tenham acesso ao sistema Pré-consciente-Consciente. É importante destacar que recalque, para a psicanálise, é diferente de repressão. Este último diz respeito a "qualquer impulso, fora da consciência, de um conteúdo representado como desprazeroso ou inaceitável” (CHEMAMA, 1995, p. 192).
} 
autora, é da relação com a escrita do Outro que as interdições simbólicas chegarão à criança e a ajudarão a alienar-se à escrita constituída da língua. Nessa dimensão, a escrita implica recalque, porque o recalque de letras, palavras ou enunciados constituirá relações diferenciais entre as cadeias significantes no interior do texto e, por conseguinte, "a formação de relações simbólicas e imaginárias necessárias à constituição de sua escrita” (BORGES, 1995, p. 221).

Diante disso, o interacionismo em aquisição de linguagem, como um lugar teórico para a investigação da aquisição da escrita, reconhece que mesmo nas formas mais primitivas da escrita "há texto, isto é, há o Outro" (BORGES, 1995, p. 250), que representa o funcionamento linguístico-discursivo e coloca a criança na escrita, permitindo que essa seja reconhecida como sujeito em/de seus textos.

\section{CONSIDERAÇÕES FINAIS}

Tendo em conta o que apresentamos e compreendendo que outras perspectivas teóricas dedicadas à investigação da escrita infantil, como o construtivismo, por exemplo, não consideram a escrita inicial composta por produções insólitas como escrita de fato, mas sim como escrita préescolar, reconhecemos o interacionismo em aquisição de linguagem como um movimento teórico que oferece subsídios para a investigação da escrita nascente.

Dessa maneira, diante das mudanças que ocorrem na produção escrita da criança, durante sua travessia pela aquisição da linguagem escrita, compreendemos que a perspectiva teórica que abordamos possibilita o reconhecimento de "avanços" e "retrocessos" nas relações da criança com a escrita, bem como coloca em evidência que a aquisição da escrita pela criança depende de sua relação com representações simbólicas e com a materialidade de textos escritos, pois esses colocarão em cena, como vimos, uma rede de significantes que possibilitarão a emergência de novos elementos na escrita inicial.

Assim, tomando como referência o trabalho de Borges e de Bosco, concordamos que "a imersão em textos promove ou é determinante do processo de aquisição da escrita" (BORGES, 2006, p. 149), em virtude de que a criança só estabelece relações com o funcionamento da língua quando imersa na linguagem.

Nesse sentido, o reconhecimento da escrita inicial como indicativo da relação sujeito/língua permite considerar o interacionismo em aquisição de linguagem como uma alternativa para o estudo da aquisição da escrita, visto que, essa perspectiva, ao afastar-se da noção de aquisição como resultado de estágios de desenvolvimento e destacar a importância da interação da criança com a materialidade da escrita, deixa aberta ao pesquisador a possibilidade de investigar as mudanças na escrita infantil enquanto efeitos de um funcionamento linguísticodiscursivo.

\section{REFERÊNCIAS}

AIRES, S. Da quase equivalência à necessidade de distinção: significante e letra na obra de Lacan. Revista do Gel (Araraquara), Araraquara, São Paulo, v. 2, p. 215-230, 2005. Disponível em: https://revistas.gel.org.br/rg/article/view/249/180. Acesso em: 30/03/2021.

BORGES, S. X. A. A aquisição da escrita como processo linguístico. In: LIER-DE VITTO, M. F.; ARANTES, L. (org.). Aquisição, patologias e clínica da linguagem. São Paulo: EDUC, FAPESP, 2006. p. 149-159.

BORGES, S. Psicanálise, linguística, linguisteria. São Paulo: Escuta, 2010. 292 p.

BOSCO, Z. R. No jogo dos significantes, a infância da letra. Campinas, SP: Pontes, 2002. 159 p. 
BOSCO, Z. R. A criança na linguagem: a fala, o desenho e a escrita. São Paulo: Cefiel/IEL/UNICAMP, 2005. 65 p.

BOSCO, Z. R. A errância da letra: o nome próprio na escrita da criança. Campinas, SP: Pontes Editores, 2009. 288 p.

BOSCO, Z. R. Notas sobre o nome próprio na aquisição da escrita. Cadernos de Estudos Linguísticos, n. 47, p. 99-107, 2005. Disponível em:

$<$ https://periodicos.sbu.unicamp.br/ojs/index.php/cel/article/view/8637274/4996 > . Acesso em: 15 nov. 2019.

CHEMAMA, R. Dicionário de psicanálise. Porto Alegre: Artes Médicas Sul, 1995. 249 p.

FREUD, S. [1915] Repressão. In: FREUD, S. Edição Standard Brasileira de obras completas de Sigmund Freud. v. XIV. Rio de Janeiro: Imago Editora, 1969. p. 163-182.

JAKOBSON, R. [1954] Linguística e Comunicação. 21.ed. São Paulo: Editora Cultrix, 2008. 168 p.

LACAN, J. [1964] O Seminário, livro 11. Os quatro conceitos fundamentais da psicanálise. 2.ed. Rio de Janeiro: Zahar, 2008. 277 p.

LEMOS, C. T. G. Teorias da diferença e Teorias do Déficit: reflexões sobre programas de intervenção na Pré-Escola e na Alfabetização. In: Seminário Multidisciplinar de Alfabetização, 1984, Brasília. Anais do Seminário Multidisciplinar de Alfabetização. Brasília: MEC-INEP, 1984. p. 133-145.

LEMOS, C. T. G. Prefácio. In: KATO, M. (org.). A concep̧̧ão da escrita pela criança. Campinas/SP: Pontes, 1988. p. 9-14.

LEMOS, C. T. G. Língua e Discurso na teorização sobre aquisição de linguagem. Letras de Hoje, v.30, n. 4, p. 9-28, dez. 1995.

LEMOS, C. T. G. [1992] Os Processos Metafóricos e Metonímicos como Mecanismos de Mudança. Substratum/ Artes Médicas, v. 1, n. 3, p. 151-172, 1998.

LEMOS, C. T. G. Sobre a aquisição da escrita: algumas questões. In: ROJO, R. Alfabetização e letramento: perspectivas linguísticas. Campinas, SP: Mercado das Letras, 1998. p. 8-18.

LEMOS, C. T. G. Das Vicissitudes da Fala da Criança e sua Investigação. Cadernos de Estudos Linguísticos. Campinas: IEL/Unicamp, n. 42, p. 41-69, 2002. Disponível em:

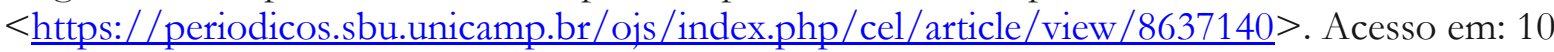
jun. 2019.

MOTA, S. B. V. O quebra-cabeça: a instância da letra na aquisição da escrita. 1995. 268p. Tese (Doutorado em Psicologia) - Pontifícia Universidade Católica, São Paulo, 1995.

Submetido em 22/01/2021

Aceito em 05/06/2021 